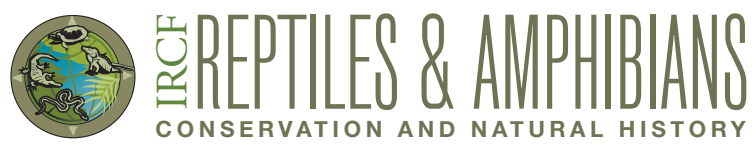

\section{Hematological Values in \\ Captive Desert Tortoises (Gopherus agassizii) from Maricopa County, Arizona}

\author{
Macario Llamas ${ }^{1}$, Christina La Croix ${ }^{2}$, Elizabeth Williams ${ }^{2}$, and William Perry Baker ${ }^{3}$ \\ ${ }^{1}$ Paradise Valley Community College, Phoenix, Arizona 85032 \\ ${ }^{2}$ Midwestern University, Glendale, Arizona 85308 \\ ${ }^{3}$ Proposed Idaho College of Osteopathic Medicine, Meridian, Idaho 83642 (wbaker@idahocom.org)
}

$\mathrm{T}$

The Desert Tortoise (Gopherus agassizii; Fig. 1), one of four species of Gopher Tortoises (genus Gopherus), is a large, terrestrial reptile native to the desert Southwest
(Dickinson et al. 2002). Adults can reach $38 \mathrm{~cm}$ (15 in.) in carapace length and weigh $6.8 \mathrm{~kg}$ (15 lbs.). Desert Tortoises are long-lived and may reach 100 years of age. They are able

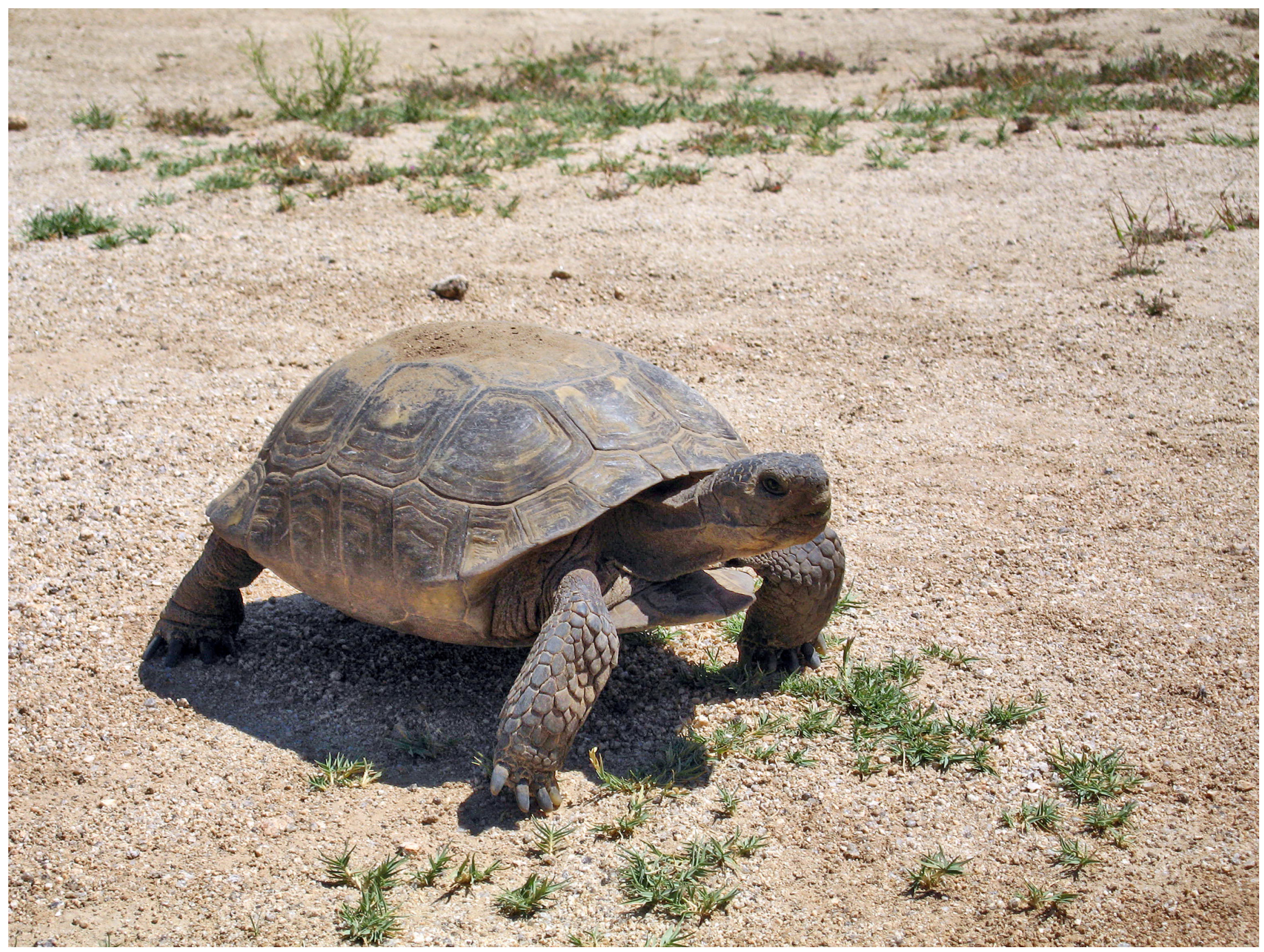

Fig. 1. A Desert Tortoise (Gopherus agassizii) in Joshua Tree National Park. Photograph by Robb Hannawacker (Joshua Tree National Park; Wikimedia Commons). 
to live where surface temperatures exceed $60^{\circ} \mathrm{C}\left(140{ }^{\circ} \mathrm{F}\right)$, but a majority of time is spent in underground burrows. They have the unique ability to obtain moisture from grasses and wildflowers eaten in the spring and can survive a year or more without access to water.

The Desert Tortoise is listed as threatened by the U.S. Fish and Wildlife Service (2017). Abundance of tortoises at 17 of 18 Sonoran Desert sites in Arizona appears to be stable or increasing (only one in the Maricopa Mountains has decreased radi- cally in size); in contrast, declining Mojave Desert populations led to the federal listing (Arizona Game and Fish Department 2010). State and federal agencies are actively involved in their preservation. While previous published studies have established baseline hematological values in free-ranging tortoises in Yavapai and La Paz Counties, limited data exist for tortoises from Maricopa County (Dickinson et al. 2002). The purpose of this study was to compare blood cell counts and differentials among animals in Maricopa County, Arizona.

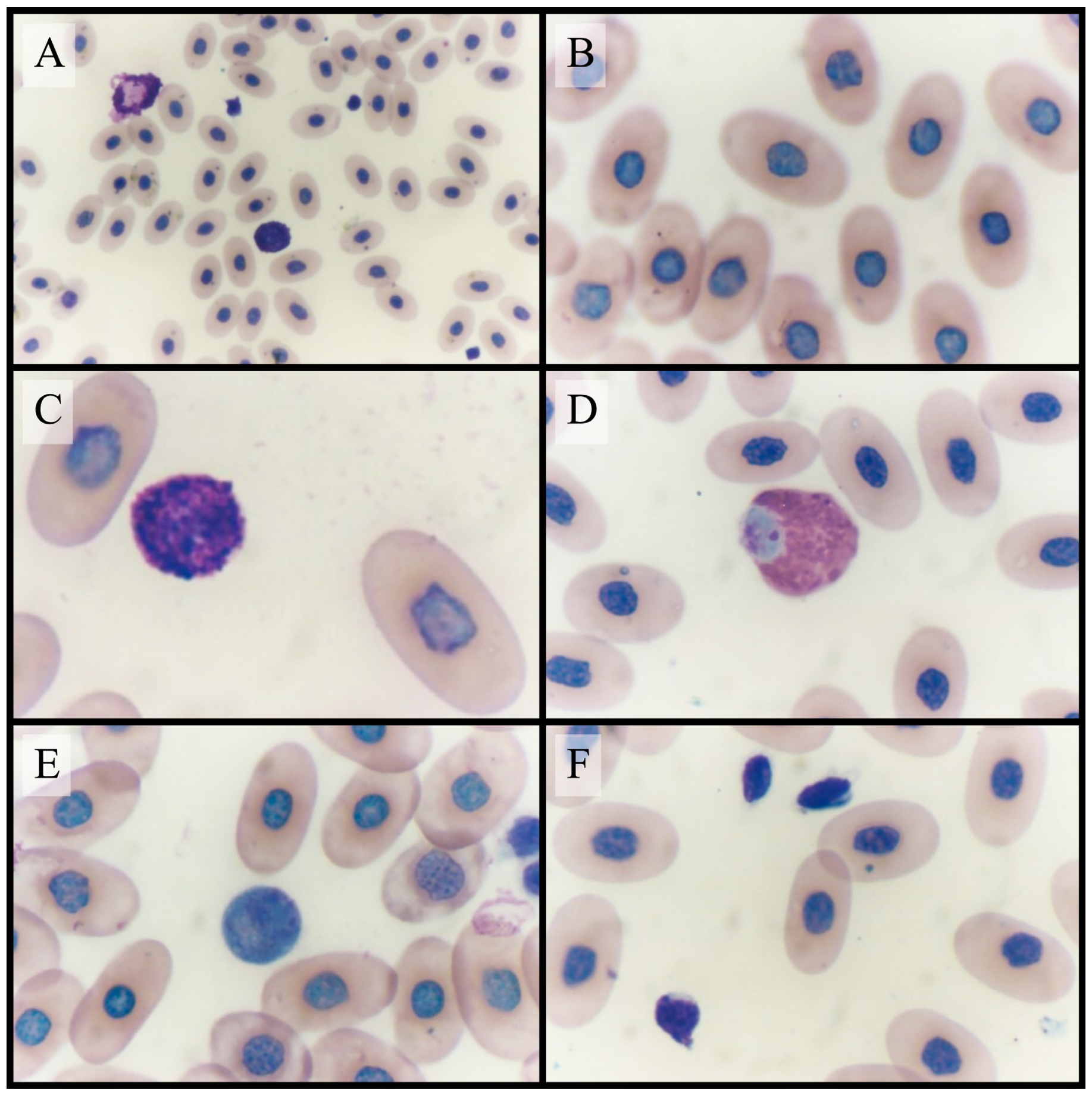

Fig. 2. Blood cells of the Desert Tortoise (Gopherus agassizii): (A) Nucleated erythrocytes (40x); (B) nucleated erythrocytes (100x); (C) basophil (100x); (D) eosinophil (100x); (E) lymphocyte (100x); and (F) platelets (100x). 


\section{Methods}

The Arizona Game and Fish Department at the Adobe Mountain Wildlife Center in Glendale, Maricopa County, Arizona provided the tortoises $(\mathrm{n}=4)$ for this study. Prior to obtaining samples, a staff veterinarian gave each animal a thorough physical examination and recorded pertinent clinical data (Frye 1991). The overall health of the tortoises was determined to be good. Age, sex, and health data are presented in Table 1.

The staff veterinarian collected blood from the jugular vein using a straight 22 -gauge needle and syringe. Following the procedure, each tortoise received intravenous replacement of fluids. The blood was collected into labeled, heparinized Becton-Dickinson microtainers. Blood smears were prepared and Wright-stained. Cells were analyzed based on standard morphological and cytochemical criteria. Two smears were

Table 1. Subject information for captive Desert Tortoises (Gopherus agassizii) used in this study.

\begin{tabular}{cccc} 
Tortoise & Age & Sex & Health \\
\hline A & 4 & undetermined & good \\
\hline B & $6-7$ & undetermined & good \\
\hline C & $25-30$ & male & good \\
\hline D & $50-60$ & male & good \\
\hline
\end{tabular}

Table 2. Blood counts and microhematocrits (mHCTs) of captive Desert Tortoises (Gopherus agassizii). Note: QNS = quantity not sufficient for this analysis.

\begin{tabular}{cccc} 
Tortoise & WBC count & RBC count & mHCTs \\
\hline A & QNS & QNS & QNS \\
\hline B & $888 / \mathrm{mm}^{3}$ & $620,000 / \mathrm{mm}^{3}$ & $25.5 \%$ \\
\hline C & $2,583 / \mathrm{mm}^{3}$ & $898,750 / \mathrm{mm}^{3}$ & $36 \%$ \\
\hline D & $416 / \mathrm{mm}^{3}$ & $425,000 / \mathrm{mm}^{3}$ & $21 \%$ \\
\hline
\end{tabular}

made for each tortoise (Alleman et al. 1992; Christopher et al. 1999; Knotkova et al. 2002; Ugurtas et al. 2003). We prepared blood cell counts using a Unopipette with a $20-\mathrm{ml}$ pipette tip and a 1:100 dilution visualized with a compoundlight microscope and 100x oil immersion lens. Both sides of a standard hemocytometer were charged with the dilution and the entire grid counted for both white and red blood cells. Microhematocrit (mHCT) was determined by spinning blood for $5 \mathrm{~min}$ in a microcentrifuge at 3,000 rpms.

\section{Results and Discussion}

Microscopic examination revealed nucleated ovalocytes (Fig. 2). Fifty red cell and nuclear measurements were performed per slide with an ocular micrometer. Average ovalocyte length was $18.0 \mathrm{~mm}$ with an average width of $10.0 \mathrm{~mm}$. The centrally located nucleus averaged $5.9 \mathrm{~mm}$ in length and $4.8 \mathrm{~mm}$ in width. Blood cell counts are presented in Table 2 and white blood cell differentials in Table 3. Although highly heterogeneous, differential counts are in keeping with those previously reported for other Desert Tortoise populations (Dickinson et al. 2002). These results provide a basis for further research to establish reference hematological values for Gopherus agassizii in Maricopa County.

\section{Acknowledgements}

We thank Jim deVos, Research Branch Chief of the Arizona State Game and Fish Department, and Sandy Cate, Coordinator of the Wildlife Center at Adobe Mountain in Glendale, Arizona, for providing us with samples and help with this project.

\section{Literature Cited}

Alleman, A.R., E.R. Jacobson, and R.E. Raskin. 1992. Morphologic and cytochemical characteristics of blood cells from the Desert Tortoise (Gopherus agassizii). American Journal of Veterinary Research 53: 1645-1651.

Arizona Game and Fish Department. 2010. Gopherus agassizii. Unpublished abstract compiled and edited by the Heritage Data Management System, Arizona Game and Fish Department, Phoenix. <https://www.azgfd.gov/w_cl edits/documents/Gophagas.fi_004.pdf>.

Christopher, M., K. Berry, I.R. Wallis, K.A. Nagy, B.T. Henen, and C.C. Peterson.

Table 3. White blood cell differentials in captive Desert Tortoises (Gopherus agassizii).

\begin{tabular}{|c|c|c|c|c|c|c|}
\hline Tortoise & Replication & Heterophil & Eosinophil & Basophil & Lymphocyte & Monocyte \\
\hline \multirow[t]{2}{*}{$A$} & 1 & 56 & 14 & 24 & 6 & 0 \\
\hline & 2 & 64 & 6 & 24 & 6 & 0 \\
\hline \multirow[t]{2}{*}{ B } & 1 & 10 & 18 & 62 & 8 & 1 \\
\hline & 2 & 25 & 24 & 52 & 4 & 0 \\
\hline \multirow[t]{2}{*}{$\mathrm{D}$} & 1 & 32 & 46 & 12 & 10 & 0 \\
\hline & 2 & 36 & 36 & 16 & 11 & 1 \\
\hline
\end{tabular}


1999. Reference intervals and physiologic alterations in hematologic and biochemical values of free-ranging Desert Tortoises in the Mojave Desert. Journal of Wildlife Diseases 35: 212-238.

Dickinson, V.M., J.L. Jarchow, and M.H. Trueblood. 2002. Hematology and plasma biochemistry reference range values for free-ranging Desert Tortoises in Arizona. Journal of Wildlife Diseases 38: 143-153.

Frye, F.L. 1991. Biomedical and Surgical Aspects of Captive Reptile Husbandry. Krieger Publishing Co., Malabar, Florida.
Knotkova, Z., J. Doubek, Z. Knotek, and P. Hajkova. 2002. Blood cell morphology and plasma biochemistry in Russian Tortoises, (Agrionemys horsfieldi). Acta Veterinaria Brunensis 71: 191-198.

Ugurtas, I., M. Sevinc, and H. Yildirimhan. 2003. Erythrocyte size and morphology of some tortoises and turtles from Turkey. Zoological Studies 42: 173-178.

U.S. Fish \& Wildlife Service. 2017. Environmental Conservation Online System (ECOS). Species profile for Desert Tortoise (Gopherus agassizii). <https:// ecos.fws.gov/ecp0/profile/speciesProfile?spcode=C04L $>$. 